\title{
Colombia Firm Energy Market ${ }^{1}$
}

\author{
Peter Cramton and Steven Stoft ${ }^{2}$
}

11 February 2007

\begin{abstract}
A firm energy market for Colombia is presented. Firm energy - the ability to provide energy in a dry period - is the product needed for reliability in Colombia's hydrodominated electricity market. The firm energy market coordinates investment in new resources to assure that sufficient firm energy is available in dry periods. Load procures in an annual auction enough firm energy to cover its needs. The firm energy product includes both a financial call option and the physical capability to supply firm energy. The call option protects load from high spot prices and improves the performance of the spot market during scarcity. The market provides strong performance incentives through the spot energy price. Market power is addressed directly: existing resources cannot impact the firm energy price. Since load is hedged from high spot prices, the market can rely on high prices to balance supply and demand during dry periods, rather than rationing.
\end{abstract}

\section{Summary}

This paper presents a market design for the Colombia firm energy market, which began on a transitional basis in December 2006 with an initial auction scheduled in November 2007.

A fundamental characteristic of the Colombian electricity market is that it is hydrodominated. Roughly $80 \%$ of Colombia's energy is produced from hydro resources, and about two-thirds of its capacity is hydro. As a result, the reliability adequacy constraint in Colombia is having sufficient thermal resources and hydro reservoirs to provide firm energy during a dry period. The proposed firm energy market provides the investment and operating incentives for suppliers to build and operate the efficient quantity and quality of energy resources. The market both reduces supplier risk and improves reliability, resulting in reliable electricity at minimum cost to consumers.

\footnotetext{
${ }^{1}$ This paper was funded by Colombia’s Comisión de Regulación de Energía y Gas (CREG). We thank the commissioners and staff for many helpful comments.

${ }^{2}$ Peter Cramton is Professor of Economics at the University of Maryland and Chairman of Market Design Inc. Over the last 20 years, he has published research on auction theory and practice in the leading peer-reviewed economics journals. During the last 12 years, he has applied this research in the design and implementation of auction markets worldwide. He has led the design and implementation of dozens of high-stake auctions in the energy and telecommunication industries. He has advised over 26 companies on bidding strategy in energy and telecommunication auctions. Since 1997, he has advised ISO New England on electricity market design, and with Steven Stoft led the design of the proposed forward capacity auction in New England. He received his B.S. in Engineering from Cornell University and his Ph.D. in Business from Stanford University.
}

Steven Stoft is an independent consultant. He is the author of Power System Economics: Designing Markets for Electricity (Wiley-IEEE, 2002). He has been an advisor to PJM's Market Monitoring Unit since 1999. He was an expert witness for the California Electricity Oversight Board and the California Public Utility Commission in the Long-Term Contract Proceeding before FERC, and for ISO New England in their LICAP proceeding, also before FERC. With Peter Cramton he led the design of the proposed forward capacity auction in New England. He received his B.S. in Engineering Math and his Ph.D. in Economics from the University of California at Berkeley. 
The market has a number of key features outlined below.

1. Product. The firm energy product is a financial call option backed by a physical resource certified as capable of producing firm energy during a dry period. The physical requirement guarantees that sufficient resources will be available to produce firm energy. The financial call option hedges load from high energy prices during periods of scarcity. ${ }^{3}$ The supplier's generating units and fuel provide a physical hedge to limit the risk of selling the call option. Indeed, relative to an energy-only market, the supplier's risk is reduced, since the firm energy market substitutes highly variable energy rents with a constant firm energy payment. The obligation is load following in aggregate: in each hour the total obligation is equal to load. A supplier's obligation in any day is equal to its share of firm energy. The obligation is distributed over the day based on the hourly dispatch. This definition-tying a unit's obligation to its hourly dispatch during scarcity-reduces market power and improves the performance of the spot energy market. A baseload unit's obligation is spread throughout the day; a hydro unit with high opportunity cost has its obligation concentrated on the peak hours of the day.

2. Planning period. Initially, the planning period - the time between the primary auction and the beginning of the supplier's commitment-is 3 years, but this will increase by six months in each successive auction, until it reaches its permanent value of 4 years. Projects with even longer lead times can sell firm energy as a price-taker up to 7 years ahead.

3. Commitment period. The commitment period for existing resources is one year. The commitment period for new resources is between one and twenty years. New resources select their preferred commitment length during the auction qualification. The firm energy price is adjusted for inflation during the commitment period.

4. Cost of new entry. A parameter in the auction is CONE, the cost of new entry. Initially, CONE is estimated by the regulator. Subsequently, CONE is adjusted based on competitive auction results.

5. Demand curve. The demand curve specifies how the purchased quantity of firm energy depends upon price. At CONE, load purchases its firm energy target (100\% of estimated firm energy demand). At higher prices, load purchases slightly less than the target quantity; at lower prices load purchases slightly more than the target quantity. The firm energy price has a ceiling of two times CONE and a floor of one-half times CONE.

6. Descending clock auction. The auction uses a dynamic auction design intended to promote price discovery. The price starts at a high price (two times CONE) and suppliers bid the quantity they are willing to supply at that price. If there is excess supply, the price is reduced and again suppliers respond with their willingness to supply. This process continues until supply and demand balance, which determines the quantity won by each supplier and the clearing price paid to all suppliers during the commitment period.

7. Price formation. The clock auction includes a simple activity rule: as the price declines suppliers can maintain or reduce quantities; quantities cannot increase. Thus, a supplier's

\footnotetext{
${ }^{3}$ Many papers have suggested the use of call options. See Bidwell (2005), Carlos et al. (2002), Chao and Wilson (2004), Cramton and Stoft (2006), and Oren (2005).
} 
offers must be consistent with an upward sloping supply curve. In addition, there is a rule that prevents existing suppliers from exercising market power. Existing resources can opt out of the market, but this choice does not impact the firm energy price paid to existing resources.

8. Performance incentives. Performance incentives largely come from the energy spot price. Those that supply more than their share during scarcity periods are rewarded and those that supply less are penalized. In each case, the marginal incentive comes from the energy spot price. In addition, a supplier's certification of firm energy depends on its estimated ability to supply firm energy in a dry period. This estimate depends at least in part on historical performance, and this provides an additional incentive.

9. Fail-safe mechanism. The auction design recognizes the possibility that there may be either inadequate supply or insufficient competition. The fail-safe mechanism specifies what happens in these unlikely events.

10. Secondary market. Shortly after the primary auction, a reconfiguration auction is held for each commitment year that has not yet occurred, but for which firm energy has already been procured in an earlier primary auction. These reconfiguration auctions allow suppliers and load to balance their positions in light of improved information. For example, a project may proceed faster or slower than anticipated, and load growth may be faster or slower than expected. In addition, a monthly auction is held during the commitment year to further balance positions. All these auctions are sealed-bid clearingprice auctions.

11. Transition. The firm energy price is set administratively in each of the first four years (2007 - 2010). During this period, the product includes the hedge for load. Beginning in 2011, the firm energy price is set in a competitive auction. The first auction is to be held in November 2007 for the 2011 commitment year. To reduce risk in early auctions when the planning period is shorter, the firm energy payment for existing resources has a tighter floor and ceiling. The floor decreases and the ceiling increases for existing resources following each of the first three competitive auctions.

These features work together to produce firm energy payments that will motivate efficient (least-cost) investment in generation resources. A critical assumption of the approach is that the market for new entry is competitive. Thus, as part of the market implementation, it is important for regulators to take steps to reduce barriers to entry. A second critical assumption is that suppliers have faith that the market, once implemented, will endure for the lifetime of new plants. Hence, it is important for the government to make a commitment to the approach and to honor the commitment. Entry barriers and political risk can undermine even the best market designs. The regulators and government must recognize and address these challenges, otherwise the market could provide high-cost, not least-cost, investment.

\section{Introduction}

This paper presents an auction design for the Colombia firm energy market. Colombia's electricity market is hydro-dominated, with about $80 \%$ of its energy coming from hydro resources and about two-thirds of its capacity. As a result, the adequacy component of Colombia's reliability constraint must assure that the system has sufficient energy during dry periods. This is accomplished by having the right blend of thermal resources together with 
sufficient reservoir capacity to meet Colombia's energy demand during a dry period. The purpose of the electricity firm energy market is to provide market-based incentives for suppliers to invest in the efficient mix of energy resources and then to operate these resources efficiently. The firm energy market is needed both to reduce investment risk and to improve the performance of the energy spot market. In this way, the firm energy market improves the reliability and efficiency of the electricity market. Consumers benefit from reliable electricity at minimum cost; suppliers benefit from market incentives and reduced risk.

The firm energy auction is a forward market for firm energy. Firm energy is the ability to deliver energy in periods of scarcity, such as during a dry period. The auction is conducted three to four years in advance of the commitment period. This allows new entrants to compete for supply, making the firm energy market contestable. Moreover, the auction coordinates the entry of new resources so as to avoid the pronounced boom-bust cycle common in most markets. The auction allows new resources to lock-in a firm energy price for up to twenty years. Existing resources receive the price set by new entry each year. All resources, both new and existing, are paid the same firm energy price, except in unusual circumstances. Moreover, this price is the same for all locations and for all types of resources.

The auction uses a descending clock format. The price starts at a high price, approximately twice the cost of new entry. Suppliers respond with the quantity each is willing to supply at that price. If there is excess supply, the price is reduced and the suppliers again specify the quantity desired at the lower price. This process continues until a price is reached in which supply and demand are balanced. This defines the clearing price, which is paid to all winning bidders throughout their commitment periods.

The quantity of firm energy demanded increases slightly as the price falls. Additional firm energy beyond the target has value for consumers, but this marginal value declines fairly rapidly. The demand curve has both a price ceiling and a price floor. The price ceiling at two times the cost of new entry (CONE) reflects the fact that entry at high prices is not limited by the price incentive, but rather other non-price constraints. The price floor at one-half CONE is intended to prevent the firm energy price from falling too low in times of surplus. This provides stability to the firm energy price, which reduces supplier risk and thus reduces consumer cost.

The descending clock auction includes important price formation features. First, to promote price discovery, there is an activity rule that requires each supplier's offers to be consistent with an upward-sloping supply curve; that is, as the price declines a supplier can only maintain or decrease its supply. Second, to prevent the exercise of market power by existing suppliers, existing supply can opt out of the market, but this choice is not allowed to impact the price paid to existing suppliers.

Performance incentives are provided primarily from the spot energy price. The firm energy product is a call option together with the physical means to produce firm energy. The total quantity of the call option follows load. The obligation is distributed over the day based on the hourly dispatch. To the extent that the supplier provides more than its obligation, it is rewarded by the spot energy price; to the extent it supplies less than its obligation, it loses the energy price, just like in a contract for differences. Hence it has exactly the same incentives as if it had not 
sold a hedge. ${ }^{4}$ If the supplier is able to shift its output to higher-priced hours, it will be rewarded. Because such shifting is rewarded, the option has no effect on performance incentives, but acts only to hedge load and suppliers. Performance incentives come from the spot energy price, as they should, and are not affected by the hedge.

An advantage of the hedge is that it eliminates the incentive to exercise market power during times of scarcity. This is because suppliers have effectively sold forward energy covering 100\% of load during times of scarcity. The forward sale improves the performance of the spot energy market during the scarcity periods, which is exactly when the market is most vulnerable to market power. Additionally, the hedge reduces supplier risk by removing the energy rents above the scarcity price, which tend to have high variance, and including them in the firm energy payment, which does not vary with weather or other factors outside of the supplier's control.

The scarcity price is a heat rate times a gas index plus other (non-fuel) variable costs. For other variable costs we use \$15.20/MWh. The gas index is the New York Harbor residual fuel oil index, averaged over the prior month, and the heat rate is $12.482 \mathrm{MBTU} / \mathrm{MWh}$, above the heat rate of all gas units. During the transition period the scarcity price is $\$ 100 / \mathrm{MWh}$.

The auction design includes fail-safe mechanisms that determine what happens in the unlikely event that there is inadequate supply offered in the auction, or there is insufficient competition.

The auction design facilitates an active secondary market. Although the primary auction is intended to procure all or nearly all of the target quantity, the purchase occurs several years in advance and circumstances may change. Thus, on an annual basis reconfiguration auctions are held, so that suppliers and demanders can balance their positions for each commitment year that has yet to occur. The reconfiguration auction is a sealed-bid clearing-price auction. Sellers submit offers and buyers submit bids, and a uniform clearing-price is determined. Trades can also occur during the year in a monthly sealed-bid clearing-price auction. Although the monthly market is likely to be extremely thin, this is not a problem, since only a small volume will be traded at the monthly price, and in any event the monthly price has both a floor and a ceiling as given by the demand curve. Bilateral trades are also supported.

Finally, the proposal includes a transition period from 2007 to 2010. Firm energy payments in these years are set administratively. Nonetheless, the product in the transition years includes the hedge at the scarcity price.

The paper is structured as follows. First we state the purpose of the firm energy market, and explain the motivation for forward procurement. Next we describe the key features of the market. We define the product, discuss the auction mechanics, and describe how price formation and performance incentives are handled. The paper concludes by addressing some of the common misunderstandings about the market.

\footnotetext{
${ }^{4}$ Note that if the supplier is short $1 \mathrm{MW}$ it must pay load the spot price minus the scarcity price, whereas if it is not short, it must still pay load this same amount but it receives the spot price. Hence the loss from being short is the full spot price and not the difference.
} 


\section{Purpose of the market}

The firm energy market has many purposes. Most importantly it is intended to induce just enough investment to maintain adequate resources. In the case of Colombia's hydro-dominated system this means having sufficient thermal generation and hydro reservoirs to provide firm energy in a dry period.

It is not enough, however, to simply have the right quantity of resources. The firm energy market should induce the efficient mix of resources, as well as the efficient operation of resources.

The firm energy market should reduce market risk, both for consumers and suppliers. This is possible by reducing the volatility of payments through a long-term contract. In particular, much of the volatility caused by weather and other short-term market fluctuations can be eliminated with the use of a financial call option. The option also improves the performance of the spot energy market by mitigating market power during times of energy scarcity.

The firm energy market must avoid market power in the firm energy auction. Since existing suppliers have significant market shares and since the required new entry is typically small relative to these shares, the incentive for existing suppliers to exercise market power is great. For the firm energy market to send a correct price signal the exercise of market power must be avoided.

The over-arching objective is, of course, to pay no more than necessary for reliable energy. This is accomplished automatically when one pursues the other objectives.

\section{Why forward procurement?}

A main feature of the design is that the procurement occurs well in advance of the commitment period. This allows new projects compete in advance of entry, before significant costs are sunk, which increases competition and produces a meaningful price. It also allows for coordinated entry, reducing the cycles of boom followed by bust, which are common in electricity markets.

The coordinated entry reduces the uncertainty in achieving the target level of resources. Some over-procurement will occur as a result of the lumpiness of investment and mistaken load forecasts, but it is not necessary to deliberately procure extra resources in recognition of uncertain entry, as would be necessary with a spot firm energy market.

A further advantage of forward procurement is that new resources set the firm energy price directly; thus, there is less reliance on a demand curve for price setting, less controversy, and less price volatility.

With forward procurement, it is possible to make a long-term commitment for new resources. This reduces investor risk and sends a price signal for new investment that is directly related to the cost of new entry.

\section{Key features}

We now discuss each of the key features of the market in detail. 


\subsection{Product}

The product definition is essential to the market. Indeed, poor product definition was a main source for the failure of earlier firm energy markets. In the case of Colombia, the binding reliability constraint is having sufficient firm energy during scarcity events. The main scarcity event is seasonal scarcity as the result of depleted hydro reservoirs and low inflows during dry periods. Spot scarcity can also occur as a result of outages, but this is unusual.

Scarcity events are defined by a high spot energy price. The energy price is a transparent measure of scarcity. Everyone sees the energy price and participants are used to forecasting the energy price. Moreover, a high scarcity price is a reliable measure of scarcity. High scarcity prices occur either from scarcity or from an exercise of market power. Given other features of the product, which address market power in the spot energy market, the price signal from the spot energy market should be an excellent measure of scarcity.

The product is a firm energy-backed energy option. Firm energy is defined by the energy delivery capability in a worst-case benchmark-a dry period. Each resource is certified both for its nameplate capacity (maximum output rate), and its firm energy (average energy output rate in worst-case benchmark). A typical thermal unit is certified at something close to its nameplate capacity, such as $92 \%$ of nameplate. The reduction from $100 \%$ reflects the units unavailability due to outages. In contrast, a hydro resource's firm energy may be well below its nameplate, say $35 \%$, due to a limited water reservoir and low inflows during dry periods.

The scarcity price of the call option is a gas index times a heat rate plus other (non-fuel) variable costs. The gas index is the New York Harbor residual fuel oil index, averaged over the prior month. This index is currently being used in Colombia and has the advantage that it cannot be manipulated by any market participant. For other variable costs we use \$15.20/MWh. The proposed heat rate is $12.482 \mathrm{MBTU} / \mathrm{MWh}$. This heat rate is higher than the heat rate of existing gas thermal units. This means that when the energy price is above the scarcity price, all thermal units would like to provide energy. New thermal peakers have heat rates of between 9 and 10 MBTU/MWh.

Some have argued for a much higher scarcity price. ${ }^{5}$ The view is that by providing price coverage from high spot prices, we are undermining bilateral contracts for energy. Our view is that the incentives for bilateral contracting are still strong, and moreover, the lower scarcity price improves the performance of the spot market, and thereby makes negotiating bilateral contracts easier. The problem with relying too heavily on bilateral contracts for price coverage is that doing so expands market power in the contracting market. A lower scarcity price reduces the potential for market power in the market for energy contracts, because it limits threats to exercise market power in the spot energy market.

The firm energy target is the best forecast of energy demand in the commitment year, accounting for load growth. This is the quantity of firm energy that is procured when the firm energy price equals CONE. The firm energy target for 2010 is shown below as the area under the load duration curve, accounting for load growth from the present.

\footnotetext{
${ }^{5}$ See Oren, Shmuel S. (2004), “Ensuring Generation Adequacy in Competitive Electricity Markets,” EPRI, Palo Alto, CA.
} 


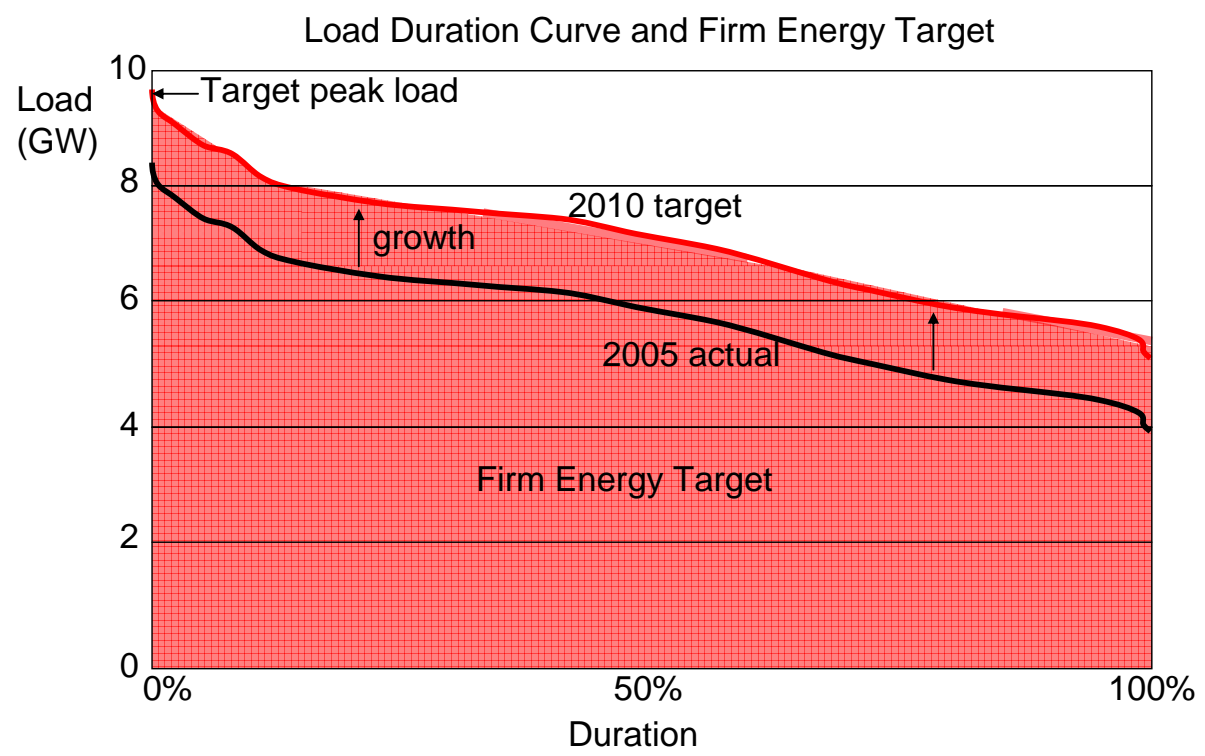

In this design, there is a single product and a single price. Remarkably, this is all that is needed for efficiency. The reason is that in Colombia's hydro-dominated system, there is a single reliability constraint: having sufficient firm energy to cover a dry period. This single constraint implies single product and single price.

If Colombia had a locational spot energy market with locational marginal prices, as in many markets in the United States, then it would be desirable to consider a zonal firm energy market, where locational constraints are modeled as well, but such considerations are not relevant in a system with a non-locational spot energy market. The spot market necessarily has stronger locational needs than the forward market, which averages hourly locational impacts across the entire commitment period.

Each new resource is certified for its incremental contribution to the firm energy constraint. For thermal units, the certification is updated periodically based on historical performance.

The product, then, is firm energy plus a mandatory hedge.

Firm energy is the unit's expected energy contribution to the system during the worst-case benchmark. A new unit's firm-energy contribution is how much less energy the system would have without the unit in the worst-case benchmark. ${ }^{6}$ The same calculation is made for a hydro or fossil resource. The approach is the same for existing units with one exception. For existing units, collectively facing a delivery constraint, such as a gas line constraint, the firm energy of the constraint is shared proportionally.

The mandatory hedge is the call option for energy at the scarcity price. The obligation is load following in aggregate: in each hour the total obligation is equal to load. A supplier's obligation in any day is equal to its share of firm energy. The obligation is distributed over the day based on the hourly dispatch. This definition—tying a unit's obligation to its hourly dispatch during scarcity—reduces market power and improves the performance of the spot energy market.

\footnotetext{
${ }^{6}$ This definition has been designed to remain correct even if high-marginal-cost fossil units eventually find they are not required during some off-peak hours during a period of scarcity.
} 
A baseload unit's obligation is spread throughout the day; a hydro unit with high opportunity cost has its obligation concentrated on the peak hours of the day. During scarcity hours the hydro opportunity cost sets the price and thermal resources run at capacity if available.

One might think that this approach is biased against hydro resources, since hydro is asked to do more load following than the thermal resources. Indeed, there would be a bias if loadfollowing was scarce; however, since there is a surplus of capacity, the capability is efficiently priced at zero. Later we discuss how the market can be adjusted to accommodate scarcity of both capacity and firm energy.

The sale of the hedge does not distort a suppliers incentive to perform. The primary incentive is still coming from the spot energy price. Thermal suppliers have an incentive to generate as much as possible during scarcity hours, and hydro units have an incentive to produce their limited energy in the highest-priced hours. To the extent a hydro supplier can shift its output to higher-priced hours, the supplier is rewarded.

The purchase in the firm energy auction is translated into an obligation for each supplier in each day, and each hour based on the hourly dispatch. If less or more than the target is purchased, this is reflected in the aggregate supplier obligation. For example, if $99 \%$ of the target firm energy is purchased, then the aggregate supplier obligation is $99 \%$ of load in each hour; load is unhedged for $1 \%$ of the load that is not purchased. If $101 \%$ of the target is purchased, then the aggregate supplier obligation is $101 \%$ of load in each hour; load is over-hedged by $1 \%$.

Load's purchase is based on a forecast of load. There will be deviations between the forecast and the actual load. As a result, a true-up at end of each month is done to adjust for deviations between the monthly target and actual monthly load. Thus load may purchase in auction $100 \%$ of its (forecasted) target, but then we observe in the month that actual load is $102 \%$ of month's target, then obligations are scaled down by 100/102. Penalties and rewards are calculated on this basis. The implication of this adjustment is that the risk from unanticipated load growth is born by load, not by suppliers.

The settlement of the option is just like settling a conditional contract for differences in each hour. If the spot price is no more than the scarcity price, then there is no obligation. If the spot price is greater than the scarcity price, then we settle differences:

$$
\text { reward or penalty }=\left(\mathrm{Q}_{\text {supplied }}-\mathrm{Q}_{\text {obligation }}\right) \times\left(\mathrm{P}_{\text {spot }}-\mathrm{P}_{\text {strike }}\right) \text {. }
$$

Just like with a contract for differences, the supplier's penalty for not meeting its obligation is the same as the supplier buying from the spot market to satisfy obligation. Notice too that the outcome is the same if it is done on a unit basis or a portfolio basis. Thus, the supplier optimizes its portfolio just as it would without the call option.

\subsection{Planning period}

The time between the auction date and the start of commitment is the planning period. We propose a planning period of four years. This is far enough ahead of the commitment that potential new projects can compete in the auction before substantial costs have been sunk in the project. In this way, the bids from new resources can reflect the cost of new entry. It makes the firm energy market contestable and allows new entry to set the price.

This long planning period is essential. Existing resources would set the wrong price because of sunk costs and market power. We must rely on new entry to set the price. 
It should be kept in mind that some pre-auction planning and development must occur for all new projects. In particular, the project must be developed to the point that it can be qualified in the auction as a credible project. A meaningful qualification requirement is needed to discourage speculators from participating in the auction. The auction is only to include credible projects, not the wishful thinking of speculators.

In light of the importance of longer-lead-time hydro projects in Colombia, a four year planning period is probably best. However, a shorter planning period can be used in the first two auctions as follows:

1. First auction, November 2007 (2011 commitment): 3 years

2. Second auction, May 2008 (2012 commitment): 3.5 years

All later auctions (2013 commitment and beyond) would have a four-year planning period.

Certainly, some projects, such as a large hydro project cannot be completed in four years. These projects may take 6-8 years to complete. For large hydro projects, we allow the investor to lock-in the auction price from the 4-year ahead auction up to seven years ahead. The large hydro project is a price taker in the auction, since it is not selling firm energy four years head, but up to seven years ahead. At the conclusion of the auction, the investor specifies the fraction of the firm energy from the project it desires to lock-in at 4-year ahead auction price.

The total quantity of firm energy purchased by load more than four years ahead is limited by a percent of the new firm energy required in that year, based on the planning projections, as shown below.

\begin{tabular}{|c|c|c|c|}
\hline \multicolumn{4}{|c|}{ Load's Limit on Forward Purchase } \\
\hline Years ahead & 7 & 6 & 5 \\
\hline Percent lim & $40 \%$ & $50 \%$ & $60 \%$ \\
\hline
\end{tabular}

If these limits are binding, then a maximum percentage for forward sale is imposed. For example, if one supplier wants to lock-in $35 \%$ and another wants to lock-in $100 \%$, then the lockin of the second bidder is reduced from $100 \%$ to the point where the percent limit is reached. The first bidder's lock-in is not changed, provided it is not necessary to reduce the second bidder's lock in below 35\%.

This approach allows the large hydro investor to manage risk more effectively by locking-in firm energy prices over one or more auctions. Like other investors, the length of commitment, up to ten years, is specified at qualification.

\subsection{Commitment period}

The commitment period is the period over which the product is sold and payment is received.

For new resources, the commitment period is up to twenty years. At qualification, the supplier specifies the desired commitment period from one to twenty years for each of its new projects. A winning supplier locks in the firm energy clearing price for the period it specified. The price is adjusted for inflation. The long commitment period lets new resources lock-in a firm energy price, reducing risk and encouraging investment. 
For existing resources, the commitment period is one year. Unlike new resources, existing resources do not need a long commitment, since the fixed costs of existing resources are already sunk. Indeed, having a short (one year) commitment reduces risk for the supplier, since the supplier gets more draws from the price distribution. This also simplifies the supplier's decisionmaking. If there was a multiple-year commitment for existing supply, then the supplier would need to make a decision about opting out of the market during a year in which the supplier believes the firm energy price would be low relative to future prices.

\subsection{Demand curve}

The demand curve specifies the quantity that is purchased at each price. In theory, it represents the marginal value to load of additional firm energy. In practice, it makes sense to constrain the curve with both a price ceiling and a price floor. The following demand curve is proposed.

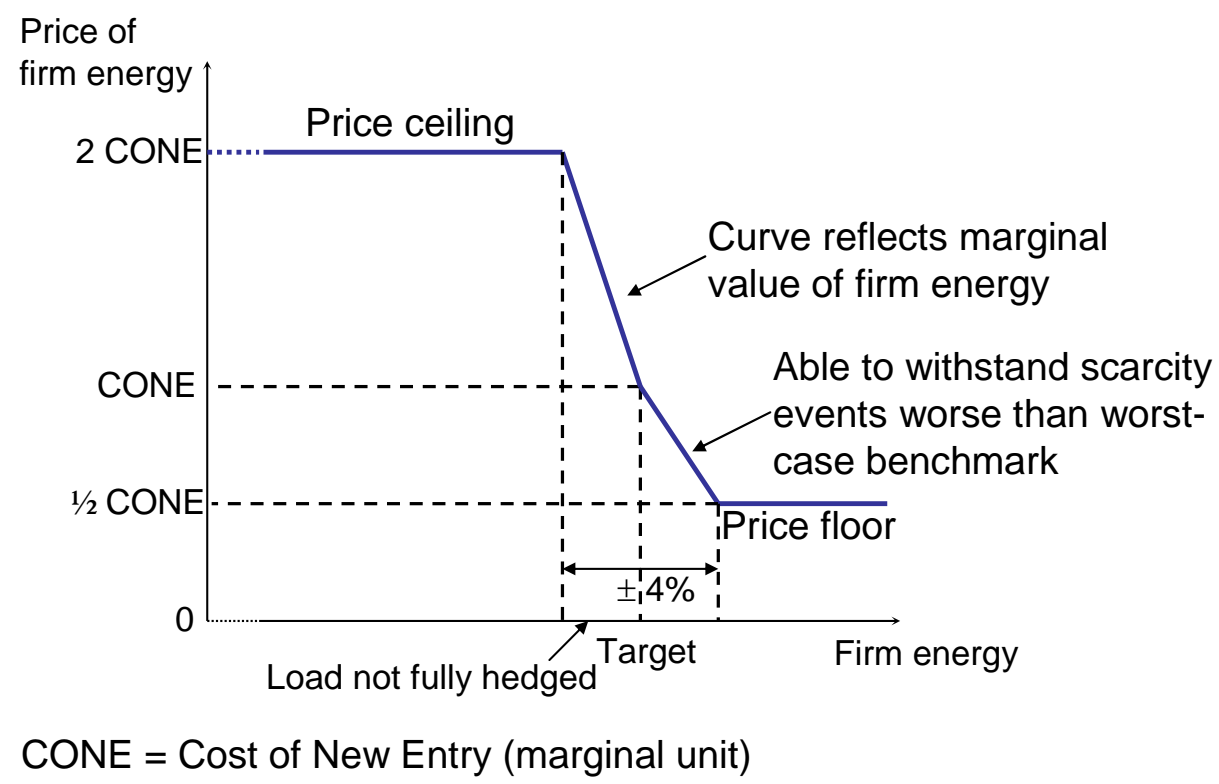

The demand curve depends on two parameters. The first is the firm energy target discussed earlier. The second is CONE, the estimated cost of new entry. CONE is initially set administratively based on a study of the cost of a new efficient peaking unit. In subsequent years, CONE is updated after every competitive auction (a competitive auction is one with sufficient competition as discussed below). In particular, if the auction this year is competitive, then

$$
\mathrm{CONE}_{\text {Next Year }}=.7 \mathrm{CONE}_{\text {This Year }}+.3 \text { Clearing Price } \text { This Year }_{\text {. }}
$$

If the auction has either inadequate supply or insufficient competition, then

$$
\mathrm{CONE}_{\text {Next Year }}=\mathrm{CONE}_{\text {This Year }}
$$

The demand curve has a price ceiling of two times CONE. At this price the auction is sending the market a strong "build" signal. If sufficient resources do not offer at this price, then it is likely that something other than price is restraining entry. Raising the price further, then, would simply result in a large wealth transfer to existing resources, rather than an expansion of new supply. 
The demand curve has a price floor of one-half CONE. The motivation for the price floor is to stabilize the price during periods of surplus, which may arise from lumpy entry in the prior year together with slow growth. The auction in this case is sending a strong "don't build" signal. Letting the price fall even further is not needed to discourage new entry. Rather it would simply increase the volatility of prices and therefore supplier risk. The bid of a supplier of a new project depends on both the expectation and variation in future firm energy prices. Having a floor on this price reduces the bid of the new entrant, because the supplier's risk is reduced as a result of the floor.

At a price of CONE, load buys exactly its target firm energy. This makes sense, since CONE is load's best estimate of the cost of new entry, load should be willing to pay CONE for its target. At higher prices, load buys a little bit less. Similar at lower prices, load buys a little bit more. The slope of the demand curve is twice as steep to the left of the target as it is to the right of the target. This reflects the fact that the marginal value of firm energy increases more quickly when we move below the target than it decreases when we move above the target. That is, near CONE the demand curve reflects diminishing marginal value for additional firm energy. The exact slopes of the demand curve above and below CONE is determined from the rule that the demand curve reaches the price ceiling when load purchases $96 \%$ of the target, and reaches the price floor when load purchases $104 \%$ of the target. This " $4 \%$ rule" is based on judgment; it will be examined further in a simulation study of the market.

\subsection{Descending clock auction}

The auction format is a descending clock. This a dynamic auction with excellent efficiency properties due to its robust price discovery. It works as follows. The auctioneer announces a high starting price. The suppliers then name quantities they wish to supply at the high price. The auctioneer determines the excess supply and announces a lower price. The suppliers again respond with quantities. This process continues until there is no longer any excess supply.

\subsubsection{Starting price}

In a descending clock auction, it is important that the starting price be set sufficiently high to create significant excess supply. Setting too high a starting price causes little harm, since competition among projects will determine the clearing price. The high starting price will quickly be bid down. On the other hand, setting too low a starting price destroys the auction. If the price is set too low, the auction would begin with either inadequate supply or insufficient competition.

A starting price of two times CONE should be high enough to assure sufficient supply is offered. If this price is not high enough, then the problem of supply is likely the result of entry barriers or faulty supplier beliefs (suppliers thinking the clearing price will be low when in fact it is high).

\subsubsection{Activity rule}

To promote price discovery, the auction has an activity rule that limits what a bidder can do later in the auction based on what it did earlier in the auction. In particular, the activity rule requires that the bidders bid in a way consistent with an upward sloping supply curve: suppliers can only maintain or reduce quantity as the price falls. 


\subsubsection{Intraround bids}

One can easily imagine a clock auction being conducted with a continuous clock. The price clock simply ticks down continuously, just like a countdown timer. This may work well if communication with bidders were perfect. In practice, however, it makes sense to conduct the auction in discrete rounds, both because communication with bidders is imperfect and because a bidder may need time to reflect on its bids. For example, in this auction, it may make sense to conduct about four rounds per day.

When a clock auction is conducted with discrete rounds, the best approach is to mimic what would happen with a continuous clock. This is done using intraround bids. In each round, the auctioneer announces: 1 ) the excess supply at end of prior round, 2) the start of round price (higher price), and 3) the end of round price (lower price). Each bidder submits a supply curve, which specifies the quantity the supplier offers at all prices between the start of round price and the end of round price. The auctioneer then determines the excess supply at end of round priceand the process continues - or if there is no excess supply at the end of round price, the auctioneer determines the clearing price, and the auction ends. Typically, supply curves are restricted to be step functions, like the one shown below.

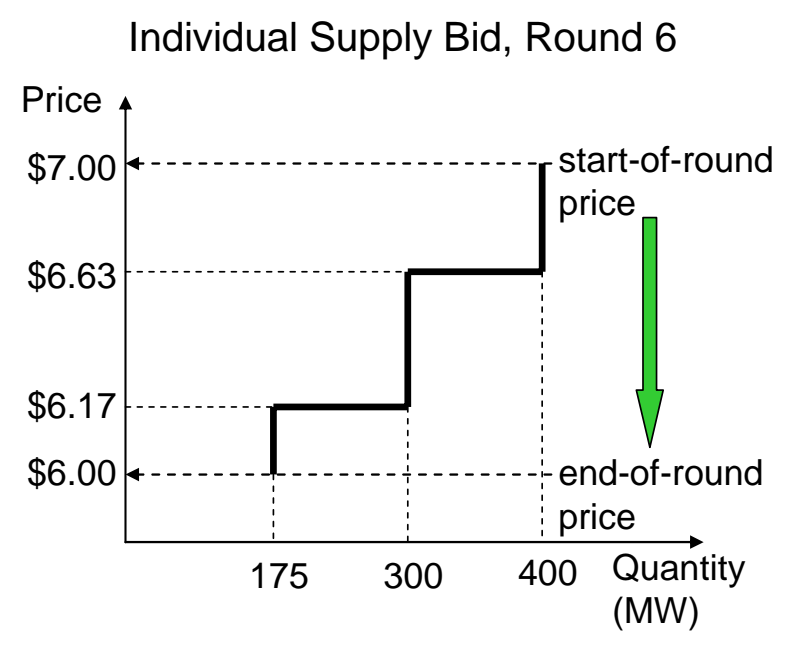

The supplier in this example is saying that it wishes to supply $400 \mathrm{MW}$ at prices between $\$ 7.00$ and \$6.63, $300 \mathrm{MW}$ at prices between \$6.63 and \$6.17, and $175 \mathrm{MW}$ at prices between $\$ 6.17$ and $\$ 6.00$.

The use of intraround bids enables the bidder to name the prices at which it wishes to reduce its quantity. Clock auctions without intraround bids generally only allow bidders to express supply at the end of round price in each round. The advantage of intraround bids is that it allows the auctioneer to have a significant decrement between rounds without reducing the efficiency of the auction. Intraround bids also make ties much less likely, and allow the auctioneer to better control the pace of the auction.

The figure below illustrates a descending clock auction with intraround bids. 


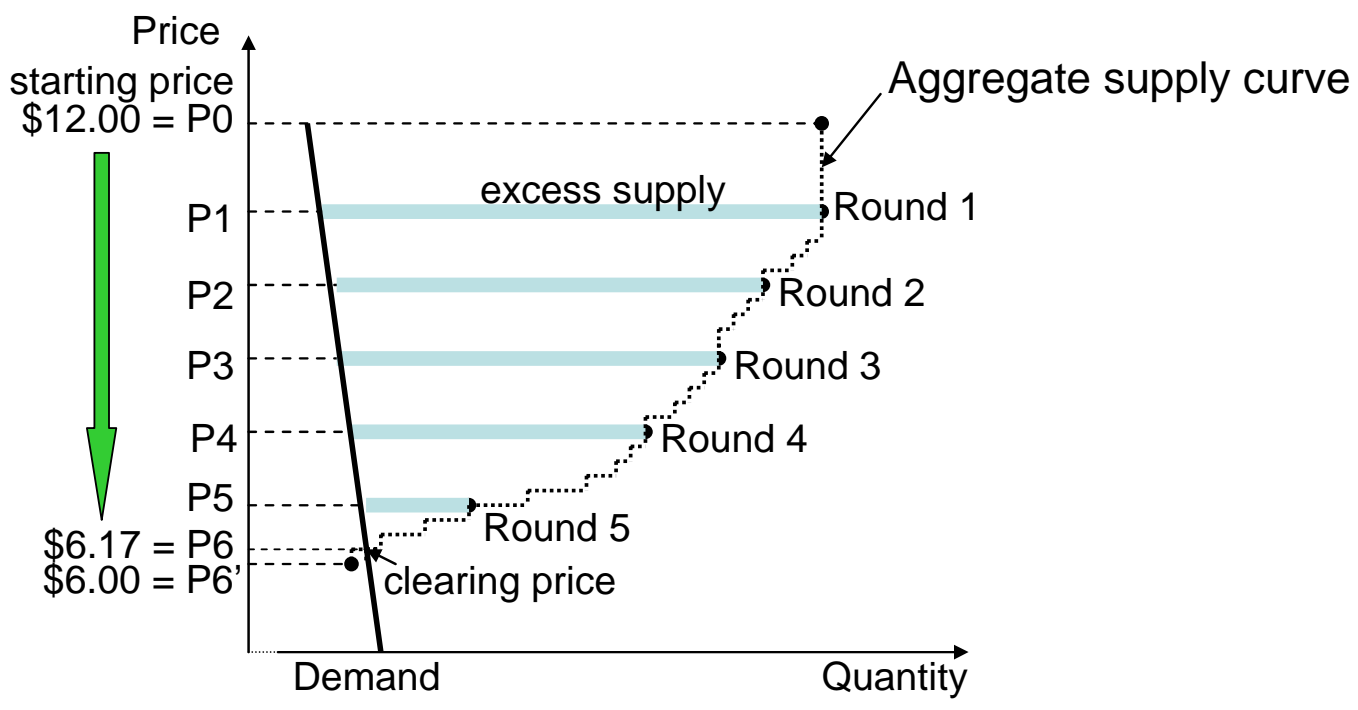

\subsubsection{Information policy}

An auction's information policy specifies what the bidders know when they place their bids. In this auction, the auctioneer announces the demand curve and starting price before auction. After every round, the auctioneer reports excess supply at the end of round price, and the end of round price for the next round. The next round's end of round price is determined from the extent of excess supply.

Supply by resource type (hydro, baseload, and peaker) is also reported after every round. For this purpose, peaker is defined as a gas unit with a heat rate above $9 \mathrm{MBTU} / \mathrm{MWh}$. This information is useful to the bidders, since the profitability of a unit generally depends on the distribution of unit types. For example, the presence of one large new hydro project will reduce the profitability of a second new hydro project.

The auctioneer does not report the supply bids of the individual bidders. This kind of detailed information is typically not needed for price discovery, but it could be used as part of strategies to support tacit collusion. This is the reason the individual information is not reported. In contrast, the aggregate information about excess supply is useful because it helps a bidder decide questions such as whether it could get two $100 \mathrm{MW}$ units accepted or only one, and because of economies of scale, it will want to bid a different price depending on this answer. We do not need to know the details of such considerations because there is a general result that knowing more about market conditions improves decision making and efficiency. The descending clock auction provides such information.

\subsubsection{Lumpy investment}

The auction respects the fact that projects are lumpy. Generating units come in discrete lumps. A supplier with a $500 \mathrm{MW}$ new project would be quite upset if it participated in the auction and found out that it won in the auction, but it only won $10 \mathrm{MW}$, not the full $500 \mathrm{MW}$ it offered. To avoid this problem, the bidder's supply curve is interpreted as discrete quantities. For example, with the supply curve above the supplier is offering the quantities of 400, 300, and 175; other intermediate quantities are not offered. In this way, the supplier need not fear partial acceptance. However, the lumps bid by the supplier must correspond to the supplier's discrete physical generating units. 


\subsubsection{Clearing rule}

With lumpy bids, it is generally not possible to have exact market clearing, where supply exactly equals demand. The question then is how is the clearing price determined and who are the winners. The rule in this auction is straight-forward. The auction is run until there is no excess supply. There are two possible cases illustrated in the figure below.
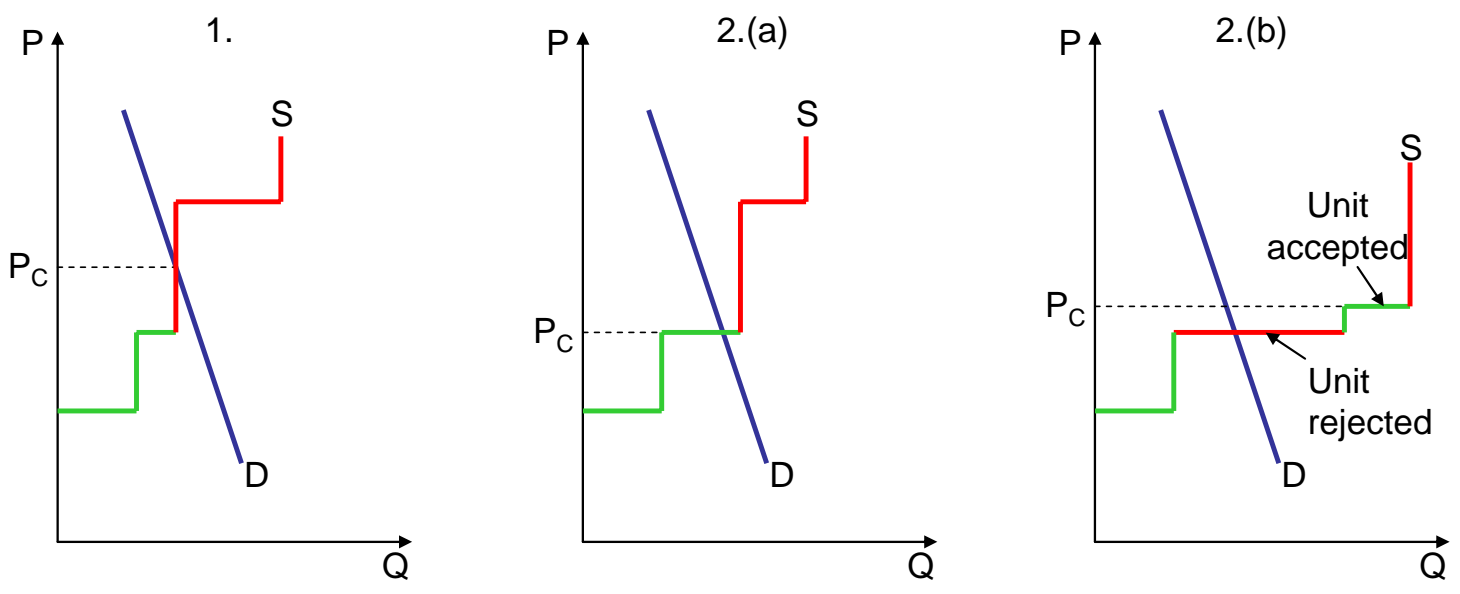

1. The shift from excess supply to excess demand occurs on a vertical supply step. In this case, we have exact clearing at the price $\mathrm{P}_{\mathrm{C}}$.

2. The shift from excess supply to excess demand occurs on a horizontal supply step. In this case, the clearing is not exact. There are two possibilities: (a) clearing occurs on the horizontal step that intersects demand, and (b) clearing occurs at a higher step and the large lump at the lower step is rejected. Whether (a) or (b) occurs depends on which option maximizes net value, which is the area under the demand curve minus total cost.

If multiple bidders drop at the clearing price, the group of bids that is accepted is chosen to maximize net value.

\subsection{Price formation}

Addressing market power in a firm energy market is essential. There is a strong incentive for existing resources to exercise market power. The reason is that the largest suppliers have significant market shares, existing resources have substantial sunk costs, and new resources are only a tiny fraction of the total. As a result, any of the largest suppliers could unilaterally set the clearing price by withholding supply.

Long-term price signals are more stable and efficient if determined from competitive forces, rather than market power. We therefore propose a simple and direct method of addressing supplier market power.

New firm energy bids are not mitigated in any way. A critical assumption is that the market for new resources is competitive.

Existing resources can opt out of the market with either an opt-out bid or a retirement bid.

An opt-out bid is used by a supplier to opt out of a single commitment year. If the price falls below the supplier's opt-out bid, the supplier will not have any obligation during the 
commitment year. The supplier can still participate in the energy spot market, but it will not receive any firm energy payment. Opt-out bids are not revealed during the auction. Moreover, opt-out bids cannot impact the price for existing supply. Opt-out bids may be rejected for reliability reasons, in which case the supplier gets a reliability must run payment.

A retirement bid is a permanent opt out of the firm energy market. Retirement bids are submitted four weeks before the start of the auction. Accepted retirements are excluded from any future firm energy payments. Retirements may be rejected for reliability reasons, but only if the reliability problem cannot be resolved during the planning period with alternative actions, such as transmission upgrades or new resources. Retirements are posted as soon as they are accepted. Retirements are replaced with new resources in the auction. They are represented as a shift to the right in the demand curve for all prices below the retirement bid.

With this approach to market power new resources almost always set the price. The demand curve sets the price in surplus years in which new entry is not needed. Retirements occasionally set the price. Other than retirements, existing resources never impact the price.

Accepted opt-out bids are replaced with new resources as follows. First the auction is run ignoring the opt-out bids, and the clearing price is set as above. This is the clearing price for all existing resources. Then we replace the accepted opt-out bids by marching up the supply curve revealed in the clock auction until all the opt-out bids are replaced, with the exception that we stop replacing opt-out bids if it would entail a price increase of more than $30 \%$ from the original clearing price. Any additional replacements occur in the first reconfiguration auction.

All new resources receive this higher price. However, existing resources receive the original clearing price.

\subsubsection{Repower bids}

Repower bids are intended to allow an existing supplier to replace one or more old units at an existing site with new units. The bid is a combination of a retirement of the old unit together with the entry of the new unit. There are two possible outcomes depending on whether the repower bid is accepted. If the repower bid is accepted, then the old unit retires and the new unit is added. If the repower bid is rejected, then nothing changes - the old unit continues to supply firm energy as before.

Repower bids raise an important issue. Replacements take time, and hence require the old unit to be down for a period of time. The required downtime depends on the size of the replacement and the configuration of the site. There are two typical cases.

Case 1: Quick switchover. If it is possible to build the new unit adjacent to the old unit, then the downtime could be limited to a few months. In this case, the downtime would be handled well through the monthly market. The supplier would simply buy in the monthly market the extra firm energy needed, and would likely schedule the downtime in the low-load months.

Case 2: Extended down time. If the new unit needs to be at the same physical location as the old unit, then the downtime could be much more than a year. This is problematic, since the retirement would occur before the replacement is online. In this case, the supplier places a retirement one or more years ahead of the replacement unit's new entry bid. The supplier is unable to couple the retirement and the new resource bid. The repowering would be done only if the supplier felt it profitable to introduce the replacement. For example, suppose a replacement 
requires two years of downtime of the old unit. The replacement can be operational in 2013, but only if the existing unit is down in 2011 and 2012. Then in the 2007 auction for the 2011 commitment year, the supplier submits a retirement bid. Then in 2009, the supplier submits a new resource bid for the replacement unit. Case 2 is not actually a repower bid, but rather a sequence of a retirement bid and a new resource bid.

We now return to case 1 in which the downtime is less than one year. Then the replacement is effectively instantaneous, and any downtime is managed by the supplier using the monthly balancing market. The repower bid still needs to be submitted at the time of the retirement bids. However, the repower bid, like a new resource bid, is eligible to set the price. The only restriction is that the new unit must be at least as large in firm energy as the old unit.

As an example, suppose a $200 \mathrm{MW}$ unit is replaced by a $300 \mathrm{MW}$ unit. The new unit is sited adjacent to the old unit, so the downtime is limited to four months and this is scheduled in the wet season. The supplier submits a repower bid during qualification, which specifies the price of $\$ 8$ for the $300 \mathrm{MW}$ unit. At the bid price of \$8, the aggregate supply curve has a horizontal step of $300 \mathrm{MW}$ (to the right) and the demand curve has a horizontal step of $200 \mathrm{MW}$ (to the left), indicating that the repower bid will be accepted for prices greater than $\$ 8$ and rejected for prices below $\$ 8$. The net impact is a $100 \mathrm{MW}$ addition to supply at prices above $\$ 8$. The repower bid is eligible to set the price.

\subsection{Performance incentives}

The performance incentive comes primarily from the energy spot price. This is not changed by the call option hedge. The hedge assures that normal performance will receive the normal reward in wet and dry periods alike. Every extra MWh of energy is rewarded the same with or without the hedge. Hedged resources still face the energy spot price at all times. Those that perform better receive more; those that perform worse receive less. The amount more and the amount less are determined from the energy spot price.

A major benefit of the hedge is that it removes market power in the spot energy market during times of scarcity. Also since load is fully hedged from high spot prices, it is possible to increase the price cap well beyond the current cap. This can be done without fear that it will destabilize the spot market. Rather, raising the price cap will make the spot market perform better by reducing the importance of the non-market response to scarcity: rationing, reservoir limits, and force majeure clauses. Only by raising the price cap can we expect demand response mechanisms to be developed.

An additional incentive to perform is the impact on the certified firm energy a unit is able to bid in the auction. Future certification is based on expected performance, and this measure responds to historical performance. Under-performing units are downgraded, and overperforming units are upgraded. The difficulty, especially for hydro resources, is that the resources ability to provide firm energy in dry periods is only rarely tested.

\subsection{Fail-safe mechanism}

It is important that the auction have protections in case the auction fails from either inadequate supply or insufficient competition.

Inadequate supply occurs if, at the starting price, there is insufficient supply of firm energy. In this case, new resources are paid the starting price. Existing resources are paid 1.1 CONE. 
Note that this rule does not discourage new projects. New projects are rewarded handsomely. This reward should encourage the market to provide more new projects in the next auction.

A second, less severe, failure is insufficient competition. Insufficient competition occurs if (1) existing resources, less retirements, is less than demand at the starting price, and (2) at the starting price, the firm energy bid exceeds the demand but there is less than $4 \%$ excess, or a single supplier's new resources are pivotal (i.e., the supplier can unilaterally push the price to 2 CONE by withholding its new projects).

An additional requirement is needed to assure enough competition comes from smaller players. Insufficient competition also occurs if at qualification, the quantity of new projects from small players - those with less than 15\% maximum firm-energy market share-is less than 50\% of the required new firm energy.

In the case of insufficient competition, the auction is still conducted. New resources are paid the clearing price. Existing resources are paid the smaller of the clearing price and 1.1 CONE. Again, this rule does not discourage new projects.

An auction with neither inadequate supply or insufficient competition is a competitive auction.

\subsection{Secondary market}

Given that the auction occurs so far in advance, it is quite likely that circumstances will change for one or more suppliers. A supplier may find that its new project is proceeding ahead of schedule and the supplier will be ready to supply one year ahead of time; similarly, the supplier's project may fall behind schedule, taking an extra year to complete. Also the forecast firm energy target may need revision due to load increasing faster or slower than expected. To accommodate these changes, we propose that a reconfiguration auction be held for every year following the primary auction until the commitment year is reached.

The reconfiguration auctions take place at the same time as the primary auction. For example, if the primary auction is held 4 years ahead, then reconfiguration auctions are held for $3,2,1$, and 0 years ahead. In the reconfiguration auction, suppliers submit bids and asks to balance their positions (the reconfiguration auction could also include dispatchable load).

The reconfiguration auction is a standard sealed-bid clearing-price auction. Suppliers simultaneously submit bids and asks, and the clearing price is determined. The demand curve is the same as in the primary auction, netting out firm energy already purchased and updating the firm energy target in light of new information. There is no bid mitigation.

A final centralized opportunity to trade is a monthly spot exchange during the commitment year. This exchange has monthly simultaneous clearing, using a standard sealed-bid clearingprice auction. This is just like the reconfiguration auctions, but the product is monthly, rather than yearly. Suppliers buy/sell to balance positions. Again the demand curve is the same as in the primary auction, but with an updated target.

Suppliers can also engage in bilateral contracts as they see fit, provided both the physical and financial requirements of the product are maintained. 


\subsection{Transition}

Because of the long planning period, it is necessary to have a transition period in which the firm energy price is set administratively for the years 2007 to 2010. The schedule of auctions during the first two years is shown below.

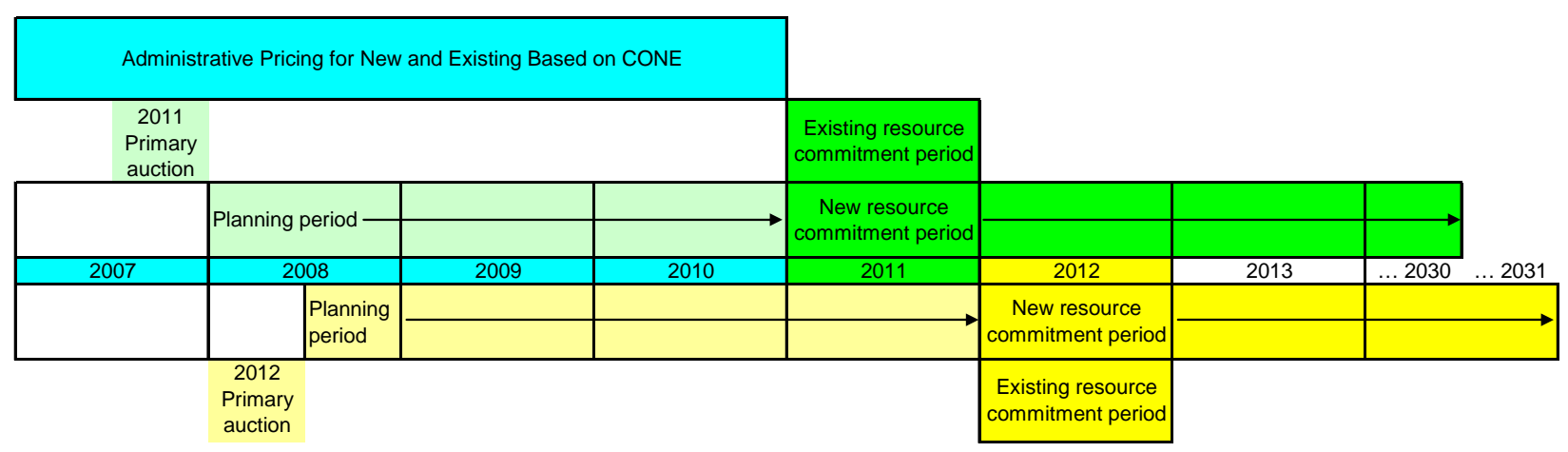

The first auction held in November 2007 for 2011 commitment has a 3-year planning period. The planning period increases by six months with each successive auction until it reaches its permanent level of four years. To reduce risk in early years when the planning period is short, the firm energy payment for existing resources has a tighter floor and ceiling. The floor and ceiling for existing resources increases following each of the first four competitive auctions, as shown below.

\begin{tabular}{|c|c|c|c|c|c|c|}
\hline \multicolumn{7}{|c|}{ Ceiling and Floor for Existing Suppliers in Early Years } \\
\hline & Transition & 0 & 1 & 2 & 3 & 4 \\
\hline Ceiling $=$ CONE $\times$ & 1 & 1.2 & 1.4 & 1.6 & 1.8 & 2 \\
\hline Floor $=$ CONE $\times$ & 1 & 0.9 & 0.8 & 0.7 & 0.6 & 0.5 \\
\hline
\end{tabular}

During the three transition years, the firm energy product includes the financial call option. The administrative firm energy price includes a premium for the cost of the energy option. This cost can be estimated from historical data as well as forecasts.

With this approach, existing energy contracts would be modified to account for the fact that the call option provides the price coverage from the scarcity price up. Fortunately, this modification is simple: the same premium is subtracted from the contract price as is added to the firm energy price, since prices above the scarcity price are now covered by the firm energy payment, not the contract. Alternatively, if load is fully contracted for the commitment years, then the contracts can stay the same, and the call option can be part of the contract.

The figure below shows how firm energy is procured, recognizing load growth, assuming that all new supply selects a twenty-year commitment period. Notice that roughly the same quantity is auctioned each year for the first twenty years, despite the load growth. After the first twenty years, the quantity auctioned will increase with load growth. 


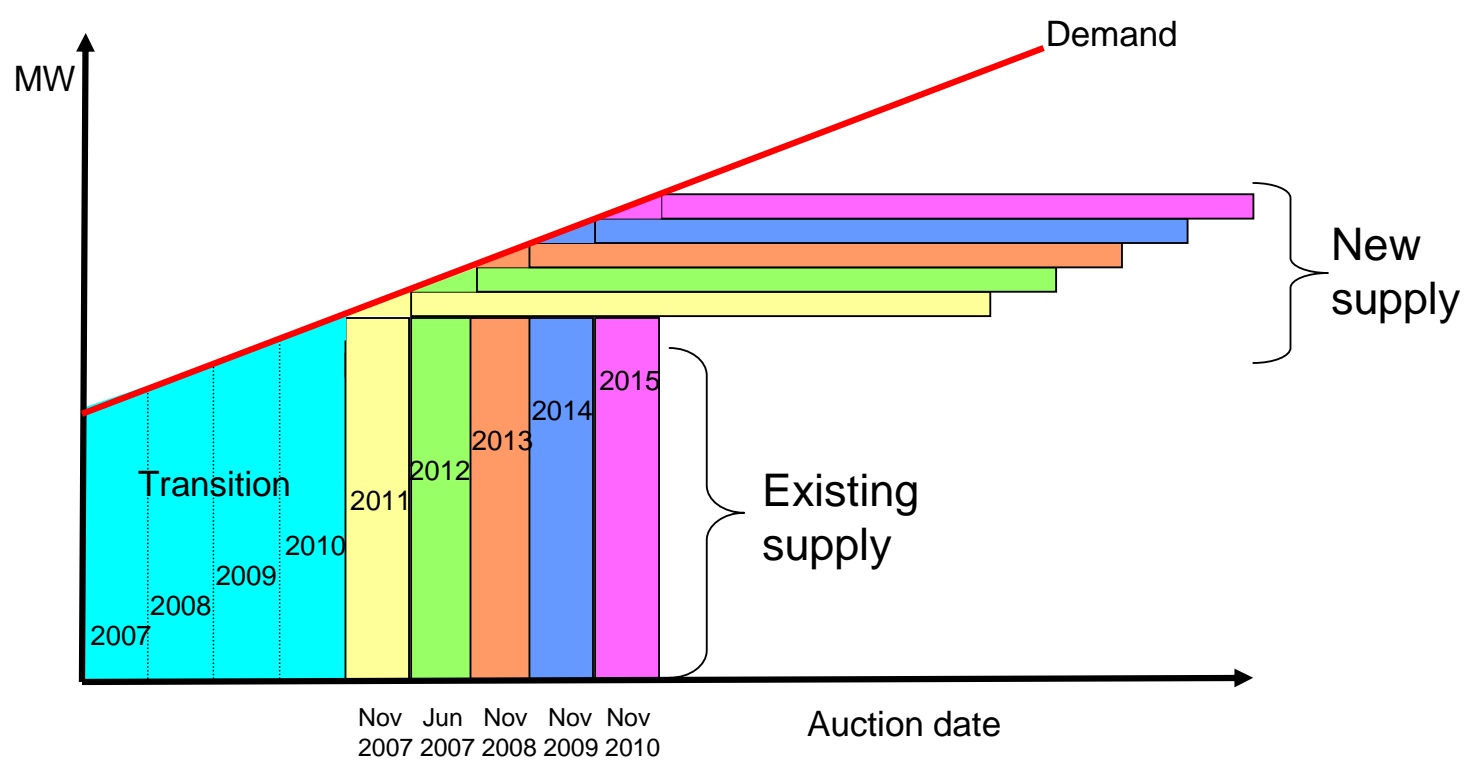

\section{Accommodating scarcity of both firm energy and capacity}

Ever electricity market requires sufficient capacity and energy to reliably satisfy load. We focus on firm energy - the ability to generate electricity in dry periods-because that is the reliability constraint that is currently binding in Colombia. Today there is roughly $13 \mathrm{GW}$ of capacity to service the annual peak of about $8 \mathrm{GW}$. There is a $5 \mathrm{GW}$ or $62 \%$ surplus of capacity. Given this surplus, it is clear that the market price for capacity is zero. Firm energy is the scarce resource, and that is what consumers should pay for. In contrast, in the electricity markets in the thermal-dominated U.S. markets, the reliability constraint is having enough capacity to handle the annual peak, so the focus there is on capacity.

Over a period of decades, it may be that the optimal mix of plants in Colombia will change in such a way that capacity becomes a binding constraint. It would be nice if the market could handle such an evolution. As it turns out accommodating scarcity of both firm energy and capacity is easily accomplished within the framework of the current design. For completeness, we sketch the approach. We do not believe at this time that it is necessary to introduce the twoproduct market, although doing so would not add any significant transaction costs, nor change market outcomes until capacity becomes scarce. Thus, the two-product market could be introduced immediately, or later, if and when it becomes plausible that the capacity constraint could begin binding.

The extension is simple. The only change is introducing a second product, capacity. As before suppliers offer resources and each resource is a package of both firm energy and capacity. The market identifies the collection of resources that satisfy both the firm energy and capacity constraints. This is done in the descending clock auction as before, but now there are two products and so two prices. In each round, the auctioneer names a pair of prices ( $\left.\mathrm{p}_{\mathrm{E}}, \mathrm{p}_{\mathrm{C}}\right)$, a price for firm energy and a price for capacity. Each supplier then decides whether, given the pair of prices, the supplier wishes to offer its resource. The auctioneer then determines the aggregate supply of both firm energy and capacity. If there is excess supply of a product, the auctioneer reduces its price, unless the price is already zero. This process continues until there is no longer excess supply of any product with a positive price. The auctioneer's goal in adjusting prices is to 
find the market equilibrium where supply and demand balance for all products with positive prices.

As before, the auctioneer uses intraround bidding, so actually offers two price pairs, a startof-round price pair, and a lower end-of-round price pair. The auctioneer is effectively asking, "As prices fall from the start-of-round price pair to the end-of-round price pair, is there any point at which you would no longer wish to offer your resource?” This question is asked each round until a price pair is found that balances the market.

In today's market, the auctioneer would know that capacity will be in surplus, even at a zero price, and so the auctioneer would quickly let the capacity price fall to zero. This is why the twoproduct market outcome would be the same as in the single-product market. Once the capacity price is zero, all that matters to the supplier is the price of firm energy.

However, with a substantially different mix of resources and a different load curve, it might be that both products would clear with a positive price. The supplier is then paid for both firm energy and capacity. This, however, is an unusual case. Since resources are a package of both firm energy and capacity, it is much more common that in order to satisfy both reliability constraints, one of the constraints is in surplus. Hence, one of the two products has a zero price in most markets.

In general, the mechanics of market clearing when suppliers offer a package of products is complex. The auction then is a combinatorial auction. There are a variety of methods for handling these package bids (Cramton et al. 2006). The most practical in this context is the clock-proxy auction, which is a particular type of clock auction that uses package bids (Ausubel et al. 2006).

\section{Common misunderstandings}

In this final section, we address a number of common misunderstandings about the proposed firm energy market.

\subsection{Approach is not used elsewhere}

This proposal integrates a number of ideas used in recent capacity market designs. For example, a similar approach was adopted in New England, which is a 32 GW system, in March 2006. The approach was approved by FERC without modification in June 2006. It is currently being implemented. There are certainly differences between the New England capacity market and this proposal. Most importantly, New England's reliability constraint is having enough capacity (rather than firm energy) to serve the peak hour in the year. A second difference is the New England market addresses market power by existing suppliers in a more complex and less effective manner. In other respects the approaches are quite similar.

All the major elements of the proposal are commonly used in markets around the world. Call options are used everywhere. The clock auction format described here has been used for many years in the United States, the United Kingdom, France, Germany, Belgium, Hungary, and Denmark for the sale and purchase of products worth in excess of US\$10 billion. 


\subsection{Call option increases risk}

Some parties have asserted that the call option increases risk. They argue that price coverage should be accomplished through forward energy contracts, rather than with call options, which impose large risks on suppliers. It is easy to see that this argument is flawed from the figure below. A forward energy contract for full price coverage is mathematically identical to a forward energy contract covering prices up to the scarcity price plus a call option covering prices above the scarcity price. Hence, it is not possible for the forward energy contract approach to involve low risk and the contract plus energy option approach to involve tremendous risk.

\section{Price Coverage}

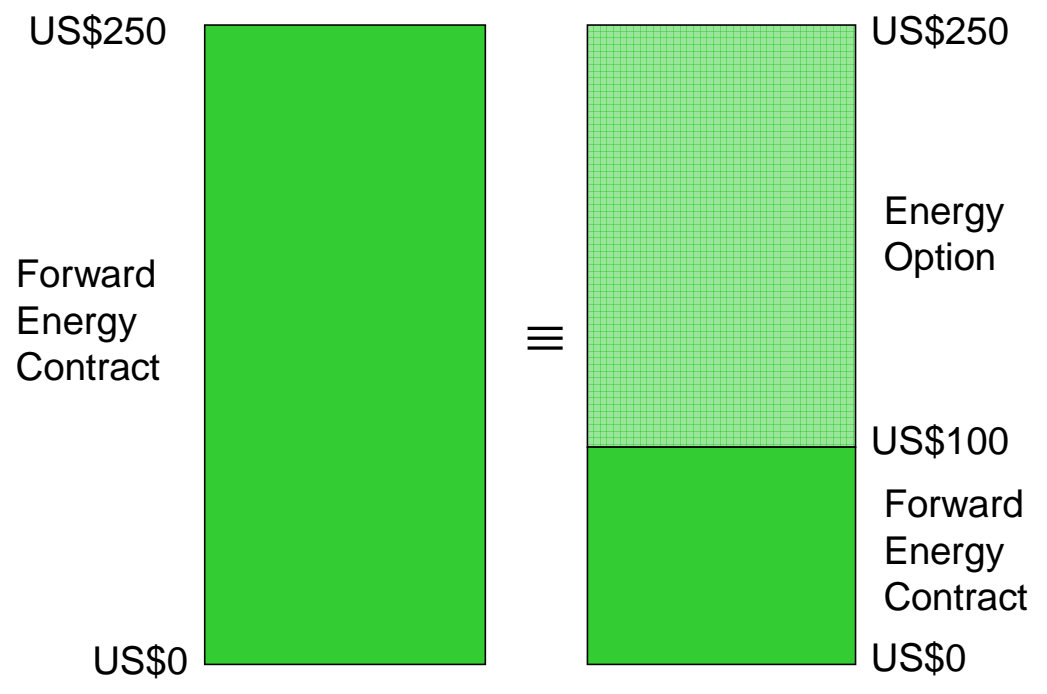

One question, then, is what is the advantage of the mandatory call option relative to simply letting price coverage come from full forward energy contracts. One advantage of the mandatory call option is that it stops the vicious cycle involving market power and risk. If a supplier sells complete call option coverage, this eliminates its market power. Hence it would only do this, if it is paid for its market power. But this is just an exercise of market power in the forward market. The result is that forward coverage is much less then it should be resulting in both too much market power and too much risk. Requiring the hedge eliminates this vicious cycle. This is possible because suppliers have a strong incentive to participate in the firm energy market, and they will willingly give up their market power in the energy market to gain this opportunity. Thus, the mandatory call option mitigates market power in the forward energy market, reducing costs and improving the efficiency of the energy market.

Another argument that the call option is very risky looks at distribution of cash flows associated with the call option and asserts that a seller of such a financial call option would have to charge a substantial risk premium. The problem with this analysis is that it assumes that the seller of the financial call option is unhedged. In that case, the call option is indeed risky. However, suppliers under this proposal have the generating unit to provide a physical hedge against this financial risk. Indeed, the only risk that the supplier faces is performance risk, and it is easily to show that performance risk is extremely low, given the performance characteristics of existing generators. Moreover, the whole point of a market approach is to improve performance and this cannot be accomplished if we eliminate performance risk. 


\subsection{Consumers will pay more}

Some have argued that consumers will pay more under this proposal, due to the substantial risk that suppliers face. Suppliers, it is argued, will need to be compensated for this additional risk. The problem with this argument is that it assumes that the market will increase supplier risk. In fact, the proposal reduces supplier risk. The only risk the supplier faces is performance risk, and this risk must be borne by the supplier in order to provide incentives for efficient operation and investment in resources. Indeed, the proposal minimizes risk while addressing market power and performance incentives. This means that consumers will pay less, not more.

\subsection{Spot energy price is not a reliable measure of scarcity}

Some have argued that the energy price is not a reliable measure of scarcity. High prices come from two sources: scarcity and market power. Given that the proposal addresses market power in the spot energy market with the mandatory call option, it must be that the high prices during scarcity events are indeed the result of scarcity.

If the spot prices are still unreliable, then the market must have another flaw, other than market power. If this is the case, the best approach is not to abandon the spot energy price as a measure of scarcity, but rather to fix the flaw in the energy market. The proposal correctly focuses attention on the spot energy price.

\subsection{Approach is complex}

Effective firm energy markets are necessarily complex, because the market must solve some serious economic problems, such as investment in the correct mix of assets, inducing investments without damaging performance incentives, and market power by existing suppliers. In fact, this proposal avoids the complexity of having administrators decide the mix of resources using a non-transparent computer program as is proposed for PJM in the United States. It also avoids complex administrative performance incentives in favor of relying on the existing spot energy price. In general it uses clear and simple market-based methods.

Other proposals based on prior capacity market designs may be simpler, but they are overly simple. For example, the prior capacity market in New England had two major flaws that led to its elimination:

1. It did not adequately address performance incentives. As a result, it failed to induce right mix of resources, and failed to induce efficient operation of resources. The approach required greater command-and-control regulation of resources.

2. It did not address market power, resulting in unstable an uneconomic capacity prices. This led to greater financial and political risk. It had higher contract costs due to the potential for exercising market power in the energy spot market, and higher energy spot prices and a less efficient energy spot market.

The current proposal avoids these pitfalls by providing strong performance incentives and by simply and directly addressing market power in the firm energy market and in the energy spot market. 


\section{Simulation of the market demonstrates its risk-reducing benefits}

In a companion paper (Cramton et al. 2006), we present a simulation analysis of the proposed Colombian firm energy market. The main purpose of the simulation is to assess the risk to suppliers of participation in the market. We also are able to consider variations in the market design, and assess the impact of alternative auction parameters.

Three simulation models are developed and analyzed. The first model (Model 1) uses historical price data from October 1995 through May 2006 to assess the performance risk of hypothetical thermal and hydro generating units. The second model (Model 2) uses historical price and operating data to assess performance risk of the actual generating units in Colombia over the same period. This analysis allows us to assess company risk. The third model (Model 3) differs from the other models in that it explicitly models the firm energy auction and investments going forward. Thus, the model is able to assess how the distribution of firm energy purchases differs from the firm energy target, and how this distribution depends on the firm energy demand curve. Model 3 also studies the investment decisions of suppliers, the impact of lumpy investments, and the impact of a higher scarcity price.

\section{Model 1: Simulated units facing historical prices}

An important output of Model 1 is the distribution of net firm energy payments for the hypothetical hydro and thermal units. A resource selling firm energy is selling a hedge for energy for prices above the scarcity price - whenever the spot energy price is above the scarcity price, the resource has an obligation to supply energy. The obligation is equivalent to a forward sale of energy at the scarcity price. Resources that over perform relative to the obligation are rewarded with the spot energy price for all extra output beyond their obligation; resources that under perform are penalized by effectively having to purchase the difference between the obligation and their output at the spot energy price. For taking on this obligation, resources receive a firm energy payment, which we assume here is equal to \$12.85/MWh in January 2006 US dollars. ${ }^{7}$ The net firm energy payment is the firm energy payment of $\$ 12.85$ plus the reward for over performance, or minus the penalty for under performance.

Our sample period includes one major dry period, which began August 1997 and ended April 1998. The dry period is characterized by frequent scarcity hours-hours in which the energy spot price is above the scarcity price of the hedge. There is a second, shorter period of high prices when the market first began, 20 November to 30 December 1995.

In addition to the net firm energy payment, we calculate the Peak Energy Rent (PER). PER is the financial cost of the hedge - the difference between the spot price and the scarcity price for the obligation quantity in each scarcity hour. This cost is about 30 percent of the total firm energy payment.

Model 1 determines the mean and standard deviation of the net firm energy payment for hypothetical generating units. We model performance risk for thermal units by assuming that the unit randomly fails and requires time to repair. Both the time until failure and the time to repair are exponentially distributed. The initial proposal for the market defined a unit's obligation as its

\footnotetext{
${ }^{7}$ In the actual market, the firm energy payment is determined in a competitive auction. In Models 1 and 2, we do not model the auction, and so assume a particular firm energy payment. All amounts are in January 2006 US dollars.
} 
proportionate share of load in the hour. Thus, a unit selling $1 \%$ of the actual firm energy demanded has a $1 \%$ obligation in every scarcity hour.

For our hypothetical thermal resource, we find that its net firm energy payment is roughly constant across all years. There is some variation in the net payment during the dry periods, but the variation is small relative to the mean. The variation is larger for resources with long repair times, since it is more likely that these units will either be running or not for extended periods. This increases risk. A second result is that the thermal units tend to under perform during dry periods. This is because they tend to produce at a constant rate, which results in a tendency to over perform during low-load hours and under perform during high-load hours. Since prices tend to be higher in high-load hours, this results in a slight penalty during the dry period.

To better match a thermal unit's output with its obligation, we consider a variation in which thermal resources have a constant obligation during scarcity hours and the hydro obligation follows the residual demand after subtracting the thermal obligation. We find that this variation does slightly increase a thermal resource's mean return during dry periods, but it has almost no impact on risk. Nonetheless, the variation is desirable, since it improves the performance of the spot market in dry periods. A supplier has little incentive to exercise market power, since the supplier enters the spot market with a nearly balanced position.

Performance risk of a hydro unit in Model 1 is modeled as a random draw of firm energy during dry periods. The hydro unit sells its expected firm energy during a dry period, but its actual firm energy may be more or less than is sold. Not surprisingly, the variation in the hydro unit's net firm energy payment is directly related to this variation in its actual firm energy. Another result is that a hydro unit tends to over perform during dry periods. This is because the hydro unit has limited water and it rationally uses this water in the highest-priced hours. As a result, the hydro unit tends to over perform during high-priced hours and under-perform during low-priced hours, and thus, it receives a reward on average.

\section{Model 2: Actual units facing historical prices and output decisions}

One limitation of Model 1 for evaluating risk is that it ignores the reality that suppliers typically own a portfolio of plants. Indeed suppliers often invest in portfolios of plants in part to reduce risk. In Model 2, we calculate the net firm energy payment for each existing generator, assuming the firm energy market was in place since October 1995. We use the unit's actual output in each hour. Each unit sells the quantity of firm energy specified in the preliminary firm energy numbers. For hydro units we calculate the net firm energy payment for both the reference quantity and the maximum quantity. The net firm energy payment includes all profits for prices above the scarcity price.

As was the case with our hypothetical units in Model 1, hydro units tend to over perform during dry periods and thermal units tend to under perform. However, because of the tendency for companies to hold diversified plant portfolios, the net firm energy payment is nearly constant across years for most companies.

Model 2 demonstrates how the hedge reduces supplier risk. Suppliers forfeit peak energy rents during dry periods for a higher constant payment that is received in all years. This stabilizes profits across wet and dry periods, and thereby reduces risk. Suppliers face some performance risk, but this risk is reduced when the supplier owns a diversified portfolio of generating units, as is common. 


\section{Model 3: Full simulation of investment decisions going forward}

Model 3 models the firm energy market going forward and thus the investment decisions of companies. There are two main inputs of Model 3. One is the set of existing resources and their preliminary firm energy numbers as updated in CREG resolution 071. The second is the hydrology output data for each of the hydro resources. We use each of the 100 ten-year series to simulate hydro output over 1000 years. We simulate the firm energy market over 1000 years (actually 50 twenty-year simulations) with benchmark parameter values. This analysis supports the risk analysis of Models 1 and 2. In addition, we are able to 1) determine how the distribution of firm energy purchases differs from the firm energy target, 2) determine the impact of lumpy investments, and 3) determine the impact of a higher scarcity price. We then consider two alternatives to the benchmark scenario. In the first alternative we double the slope of the firm energy demand curve. In the second alternative we double the price elasticity of demand during scarcity periods.

The findings are as follows.

- Lumpy investment means that few new units are added each year. Indeed, in $27 \%$ of the years no new entry occurs. (This is an overestimate to the extent that the size of winning projects reflect the actual need in the year.)

- Lumpy investments cause a negative bias in profits, since the surplus causes a reduction in energy rents. Bidders would need to take into account.

- The mandatory hedge is remarkably successful in reducing risk. In the benchmark case, the hedge reduces aggregate profit risk by a factor of 7 . More importantly, the hedge reduces company risk by a factor of 4.5 in the benchmark case. Even when we assume a high level of demand response so that prices remain low during scarcity periods and there is less profit risk to start with, the hedge reduces company risk by $55 \%$.

- A higher scarcity price increases risk. Increasing the scarcity price shifts the profit distribution toward the no hedge case (a scarcity price of infinity). This results in a large increase in energy rent risk and a small decrease in hedge payment risk. The overall impact is a large increase in profit risk.

Taken together, the simulation results demonstrate the risk reducing benefits of the firm energy market. Provided there is competitive new entry in response to load growth, the firm energy market should work well at coordinating investment in new supply, while minimizing supplier and consumer risks.

\section{Conclusion}

The firm energy market proposed here represents the current best-practice in electricity market design. Early capacity markets suffered from serious flaws that ultimately led to their elimination or replacement. The design proposed here corrects each of the earlier flaws. In particular,

1. The product is well defined as a physically-backed call option on energy. The physical requirement assures reliability. The call option improves the performance of the spot energy market in times of scarcity and reduces supplier risk. 
2. New entry is coordinated by holding the auction well in advance of the commitment period. This mitigates the boom-bust cycle that is common in electricity markets. More importantly, it allows the firm energy price to be more directly tied to the cost of new entry.

3. Strong performance incentives are maintained from the spot energy price. Additional incentives come from the link, especially for thermal resources, between historical performance and the level of firm energy certification.

4. Price formation is supported by eliminating the ability of existing suppliers to exercise market power in the firm energy market. In addition, the clock auction format is used to encourage price discovery and improve the efficiency of the auction outcome.

A successful firm energy market depends on more than good design. First, the firm energy market has at its foundation the spot energy market. It is important that the spot energy market send reliable price signals. Second, the firm energy market relies on competitive entry; hence, entry barriers must be kept to a minimum. And finally, the firm energy market depends on longrun price expectations; thus, it is important that investors have faith in the stability of the market over the long run.

\section{References}

Ausubel, Lawrence M., Peter Cramton, and Paul Milgrom (2006), "The Clock-Proxy Auction: A Practical Combinatorial Auction Design," in Peter Cramton, Yoav Shoham, and Richard Steinberg (eds.), Combinatorial Auctions, Chapter 5, 115-138, MIT Press.

Bidwell, Miles (2005), “Reliability Options,” Electricity Journal, June.

Carlos, Vazquez, Michel River, and Ignacio Perez Arriaga (2002), “A market approach to long-term security of supply," IEEE Transactions on Power Systems, 17 (2): 349-357.

Chao, Hung-po and Robert Wison (2004), "Resource Adequacy and Market Power Mitigation via Option Contracts,” EPRI, Palo Alto, CA.

Cramton, Peter, Yoav Shoham, and Richard Steinberg (2006), Combinatorial Auctions, Cambridge, MA: MIT Press.

Cramton, Peter and Steven Stoft (2006), “The Convergence of Market Designs for Adequate Generating Capacity,” white paper for the California Electricity Oversight Board.

Cramton, Peter, Steven Stoft, and Jeffrey West (2006), “Simulation of the Colombian Firm Energy Market,” white paper, Criterion Auctions.

Oren, Shmuel S. (2005), “Generation Adequacy via Call Option Obligations: Safe Passage to the Promised Land,” Electricity Journal, November. 